\title{
Discoloured seeds of amaranth plant infected by Alternaria alternata: physiological, histopathological alterations and fungal secondary metabolites associated or registered
}

\author{
María Cristina Noelting ${ }^{1 *}$, Marina Sisterna ${ }^{2,3}$, Marcelo Lovisolo ${ }^{4}$, Andrés Molla-Kralj ${ }^{4}$, \\ Gladys Lori ${ }^{2,3}$, María Cristina Sandoval ${ }^{4}$, Michael Sulyok ${ }^{5}$, Maria C. Molina,
}

\author{
${ }^{1}$ Instituto Fitotécnico de Santa Catalina, Facultad de Ciencias Agrarias y Forestales, Universidad Nacional de La Plata, CP 1836, \\ Llavallol, Buenos Aires, Argentina \\ ${ }^{2}$ Centro de Investigaciones Fitopatológicas, Cátedra de Fitopatología, Facultad de Ciencias Agrarias y Forestales, Universidad \\ Nacional de La Plata, CP1900 La Plata, Buenos Aires, Argentina \\ ${ }^{3}$ Comisión de Investigaciones Científicas de la provincia de Buenos Aires, CP 1900 La Plata, Buenos Aires Argentina \\ ${ }^{4}$ Facultad de Ciencias Agrarias, Universidad Nacional de Lomas de Zamora, CP1836, Llavallol, Argentina \\ ${ }^{5}$ Department IFA-Tulln, University of Natural Resources and Life Sciences Vienna (BOKU), Konrad Lorenz Strasse 20, CP 3430, \\ Tulln, Austria \\ ${ }^{6}$ Consejo Nacional de Investigaciones Científicas y Tecnológicas, CABA, Av. Rivadavia 1917, CP 1033, Buenos Aires, Argentina
}

Received: January 27, 2016

Accepted: June 22, 2016

\begin{abstract}
In the present study the aspects of discolouration that could influence both the production and consumption of amaranth were analyzed with the objectives to identify the presence of Alternaria alternata on seeds, to analyze possible changes in the anatomy of seed tissues and to detect the presence of fungal secondary metabolites. Component plating, histopathological and mycological analyses on discoloured seeds allowed i) location of propagules of A. alternata in all seminal components; ii) observation of hypertrophies in perisperm and embryo and iii) determination of several fungal secondary metabolites, mainly high concentrations of tenuazonic acid. To our knowledge, the information presented in this paper, related to physiological, histopathological changes and fungal secondary metabolites on discoloured seeds of (Amaranthus mantegazzianus syn. A. caudatus subsp. mantegazzianus (Pass) Hanelt affected by A. alternata, is the first worldwide record.
\end{abstract}

Key words: amaranth, fungal secondary metabolites, hypertrophies, seed pathology

\section{Introduction}

Amaranth grains were one of the main foods of various indigenous ethnic groups (Aztecs, Incas) that inhabited the Americas in ancient times (NRC 1984). Amaranth considered as nutraceutical crop and known for its nutritional value, has motivated great interest of researchers, producers and consumers in this plant. Currently, amaranth crop has spread to many countries due to its nutritional value and ability to adapt to different agroecological zones where traditional crops fail.

The nutritional characteristic is associated with a high content of proteins, essential amino acids, minerals, vitamins, fats, fibers and starches which are present in the seeds, leaves and stems of the plants (Afolabi et al. 1981; Becker et al. 1981; Makus and Davis 1984; Willis et al. 1984; Teutonico and Knorr 1985).

The seeds of high biological value can carry a diverse mycobiota composed mainly of field and storage fungi, which might damage the seeds and subsequently the crop. Alternaria alternata (Fr.) Keissler syn. A. tenuis Nees. has been reported as the main contaminant among the field fungi isolated from seeds of amaranth cultivated varieties (Bartolini and Hampton 1989; Noelting et al. 2004; Moreno-Velázquez et al. 2005; Pusz 2009a; Biasi et al. 2013).

Recently, a new disease that affects amaranth seeds, associated mainly with $A$. alternata, was reported in Argentina (Noelting et al. 2011). This disease causes a change in the colour of seeds, decreases germination and increases the number of abnormal plants. It is estimated that this pathology may be present in several cultivated areas. However, no data on the discolouration of amaranth seeds by A. alternata is available. This scarce information (Noelting et al. 2011) may be due to the difficulty in detecting the infection that goes unnoticed to naked eye because of the small size of the seeds (an average diameter $1 \mathrm{~mm}$ ).

In others crops such as wheat, A. alternata is associated with black-point, a worldwide disease affecting wheat grains (Mathur and Cunfer 1993). Symptoms of the blackpoint include a blackish discolouration around the embryo 
end (Conner and Davison 1988). The affected grain results in a lower germination rate, and a flour of poor quality with unpleasant taste, and dark color (Lorenz 1986).

Moreover, histological analysis of wheat grains affected by black-point revealed that $A$. alternata is responsible for inducing alterations in embryonic tissues, causing darkening and also loss of cell contents, its hyphae has been observed in all discoloured tissues (Agrawal et al. 1987).

As far as amaranth crops are considered, there are no reports related to histological analysis of discoloured seeds infected with $A$. alternata, detected possible alterations in seminal tissues colonized by this microorganism as well as references of possible mycotoxin contamination in amaranth seeds. In this sense it is known that fungal secondary metabolites produced by fungi affect the quality of seeds or grains and their products constituting a potential risk to consumers.

It is known that Alternaria metabolites such as alternariol, alternariol monomethyl ether, tenuazonic acid, altenuene and altertoxins have been proved to be harmful to animals (Bottalico and Logrieco 1992). On the other hand, A. alternata toxins inhibit the germination of tomato, eggplant, cucumber, okra, rice, mungbean, corn, cotton, peanut and chilli seeds (Theerthagiri et al. 2008).

The carried out research aimed at further investigation of discolouration affecting amaranth seeds in relation to location of the A. alternata propagules in the seeds, the anatomy of its seminal tissues and type, and concentration of fungal secondary metabolites present.

\section{Materials and Methods}

\section{Technique for inducing artificial seed discolouration}

In order to induce the completed discolouration of seeds with A. alternata, a deep-freeze technique was adapted and modified a difference of the previous technique (Noelting et al. 2011). Amaranth seeds with healthy appearance were disinfected in $3 \%$ sodium hypochlorite for $5 \mathrm{~min}$, rinsed three times with sterile distilled water and dried between filter papers.

The seeds were plated on Petri dishes containing four layer of filter paper moistened with $5 \mathrm{ml}$ sterile distilled water and incubated first in a growth chamber for $24 \mathrm{~h}$ under $12 \mathrm{~h}$ photoperiod at $20^{\circ} \mathrm{C}$. Then, seeds were transferred to $-22^{\circ} \mathrm{C}$ for $24 \mathrm{~h}$ and then seeds were plated on seven-day old A. alternata colonies developed on Potato Dextrose Agar (PDA) and incubated at $20^{\circ} \mathrm{C}$ under $12 \mathrm{~h}$ photoperiod for 5 days. Disinfected seeds plated in Petri dishes with PDA and without $A$. alternata colonies were considered as control. Seven days after incubation, the appearance of seeds was evaluated and compared to untreated seeds (control).

\section{Component plating of seeds}

Evaluation of seed health conditions allows detecting presence or absence of a pathogen. Both, the blotter method and deep-freezing blotter method are able to reveal Alternaria infection (Limonard 1966; Mathur and Kongsdal 2003). We used the component plating technique in order to detect fungal species located in each section of seeds (episperm or seminal coat, perisperm and embryo) on naturally discoloured seeds (S1), artificially discoloured seeds (S2) and normal appearance seeds (S3).

Forty seeds of each sample (S1, S2 and S3) were immersed in water during $10 \mathrm{~h}$, then dissected aseptically with a dissecting needle and separated into three components: seed coat, embryo and perisperm. Each component was surface sterilized for 5 min with $1 \%$ sodium hypochlorite, rinsed with sterile distilled water and placed on moisten filter papers placed in polystyrene trays (15 $\mathrm{cm}$ wide by $21 \mathrm{~cm}$ long). The trays were incubated in a growth chamber at $25 \pm 2^{\circ} \mathrm{C}$ for 7 days and then fungi were identified for each component, and occurrence and incidence of each species were recorded.

\section{Histopathological analysis}

These analyses aimed at identifying possible alterations on tissues of discoloured seeds caused by A. alternata. Forty seeds from S1, S2 and S3 were first fixed in FAA (formalin-acetic acid-alcohol) and next in paraffin by the traditional method (D'Ambroggio 1986).

Longitudinal and cross sections of seminal tissues (12 $\mu \mathrm{m}$ thick) were cut with a Minot rotary microtome. Tissue sections were stained by staining double method; safranina - fast green (D'Ambroggio 1986) and mounted on slides with a synthetic medium (PMyR) for light microscopy detailed observations.

\section{Mycological analysis}

These analyses were carried out to identify presence and validate concentration of fungal secondary metabolites in S1; S2 and S3. Seeds from each group (1 g) were first mixed with $5 \mathrm{ml}$ of extraction solvent acetonitrile/water/ acetic acid (79/20/1) and stirred for $10 \mathrm{~min}$ followed by ultrasonication for more than 10 min per sample.

Then $100 \mu \mathrm{l}$ filtered next dried and redissolved in 1,000 $\mu \mathrm{l}$ water-acetonitrile (1/1) and applied on a LC-MS/ MS system. The analysis of the fungal secondary metabolites was carried out by using multi-detection method described by Malachova et al. 2014.

The same procedure was performed to determine fungal secondary metabolites of the A. alternata strain, LPSC $\mathrm{N}^{\circ} 1085$. The strain was grown on Yeast Sucrose Extract agar (YES) at $25^{\circ} \mathrm{C}$ in darkness for 14 days, following the method described by Samson et al. 2002).

The presence of six fungal secondary metabolites, such as alternariol $(\mathrm{AOH})$, alternariol monomethyl ether (AME), tenuazonic acid (TeA), altenuene (ALT), altertoxine I (ALTX-I) and tentoxin (TEN) was determined.

The chromatographic separation was performed at $25^{\circ} \mathrm{C}$ on a Gemini C18, $150 \times 4.6 \mathrm{~mm}$ ID, 5 micron particle size, C18 equipped with a $4 \mathrm{~mm}$ ID $\times 3$ security guard cartridge (all from Phenomenex, CA, USA, UU) and coupled to a 1290 Series HPLC system (Agilent, Waldbronn, Germany). A QTRAP LC-MS/MS System 5500 (Applied Biosystems, CA, USA) equipped with a Turbo Ion Spray electrospray ionization (ESI) source was used to detect and quantify the fungal metabolites. 


\section{Results}

\section{Technique for inducing artificial seed discolouration}

Seven days after incubation seeds growing on colonies of A. alternata showed discolouration. Colour of artificially inoculated seeds was more pronounced (Fig. 1A) in relation to naturally discoloured seeds (Fig. 1B). The non-inoculated seeds showed no signs of discolouration (Fig. 1C) and the presence of A. alternata mycelium was observed in their coats.

\section{Component plating technique}

Alternaria alternata was the main microorganism detected in episperm, embryo and perisperm of naturally and artificially discoloured seeds and only on coats of normal seeds (Table 1). On the other hand, a lower fungal diversity was detected on normal seeds in relation to naturally and artificially discoloured seeds.

\section{Histopathological analysis}

The anatomy and histopathology of artificially and naturally discoloured seeds (Figs. 2A, B) differed from that normal looking seeds that showed no changes in the anatomy of their tissues (Fig. 2C).

Naturally and artificially discoloured seeds showed tissue abnormaties as hypertrophies in perisperm $(p)$ and in the embryo tissues: radicle (r) and cotyledons (co) (Figs. 2A, B).

Ecto- and endophytic hyphae of brown to dark brown colour were observed in seed coat and periperm of seeds with normal appearance and discoloured ones.

\section{Mycological analysis}

Artificially and naturally discoloured seeds displayed a higher concentration of fungal secondary metabolites in relation to normal appearance seeds (Table 2). Tenuazonic acid (TeA) was the main mycotoxin detected at high concentrations on discolourated seeds. The other important fungal secondary metabolites detected in order were: $\mathrm{AME}$ and $\mathrm{AOH}$.
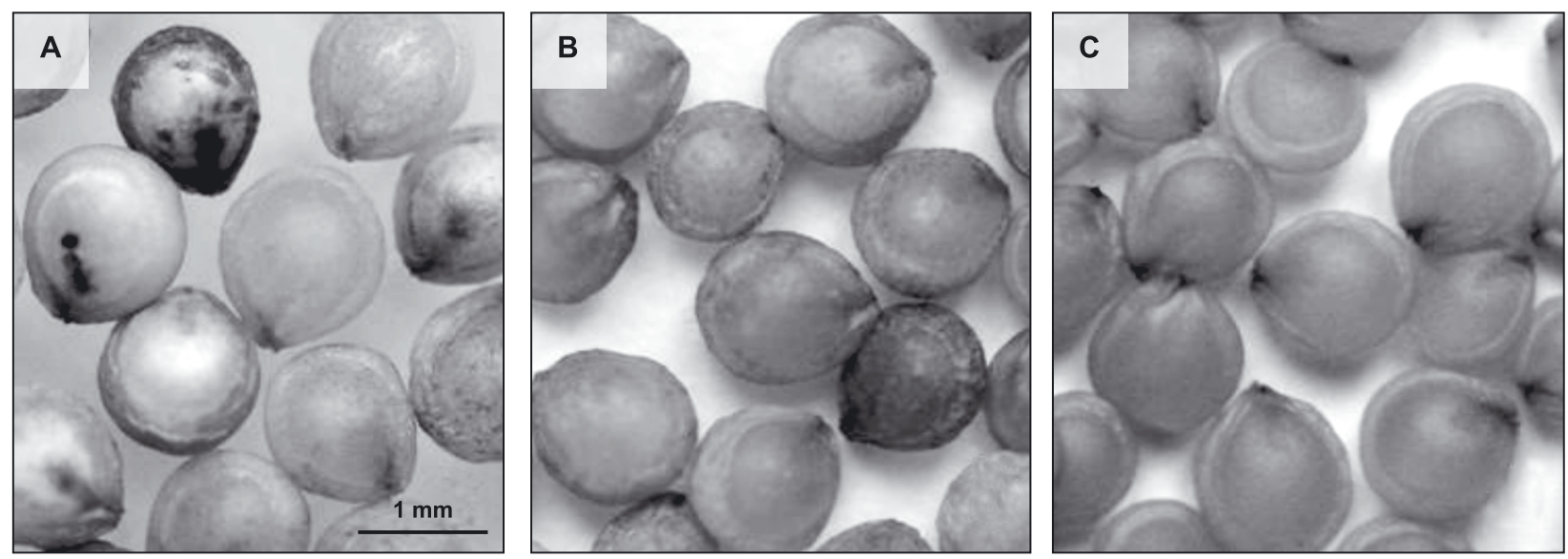

Fig. 1. Artificially (A) and naturally (B) discoloured amaranth seeds affected by Alternaria alternata; normal in appearance seeds (C)

Table 1. Fungal microorganisms isolated from seed tissues: naturally discoloured seeds (S1); artificially discoloured seeds (S2) and normal seeds (S3)

\begin{tabular}{|c|c|c|c|c|c|c|c|c|c|}
\hline \multirow{3}{*}{ Fungi microorganisms } & \multicolumn{9}{|c|}{ Seminal tissues } \\
\hline & \multicolumn{3}{|c|}{ episperm } & \multicolumn{3}{|c|}{ perisperm } & \multicolumn{3}{|c|}{ embryo } \\
\hline & S1 & S2 & S3 & S1 & S2 & S3 & S1 & S2 & S3 \\
\hline Alternaria alternata & 7.84 & 10.00 & 1.00 & 5.00 & 6.00 & 0.50 & 2.50 & 3.00 & 0.00 \\
\hline Chaetomium globosum & 0.00 & 0.00 & 1.60 & 0.00 & 0.00 & 0.00 & 0.00 & 0.00 & 0.00 \\
\hline Cladosporium cladosporioides & 0.00 & 0.00 & 2.50 & 0.00 & 0.00 & 0.00 & 0.00 & 0.00 & 0.00 \\
\hline Epicoccum nigrum & 0.00 & 0.00 & 1.00 & 0.00 & 0.00 & 0.00 & 0.00 & 0.00 & 0.00 \\
\hline Fusarium oxysporum & 2.64 & 0.00 & 0.00 & 0.00 & 0.00 & 0.00 & 0.00 & 0.00 & 0.00 \\
\hline Mucor sp. & 0.00 & 0.00 & 0.50 & 0.00 & 0.00 & 0.00 & 0.00 & 0.00 & 0.00 \\
\hline Non identified & 0.00 & 0.00 & 1.00 & 0.00 & 0.00 & 0.00 & 0.00 & 0.00 & 0.00 \\
\hline
\end{tabular}

*values are the average percentage incidence of each isolated microorganism 

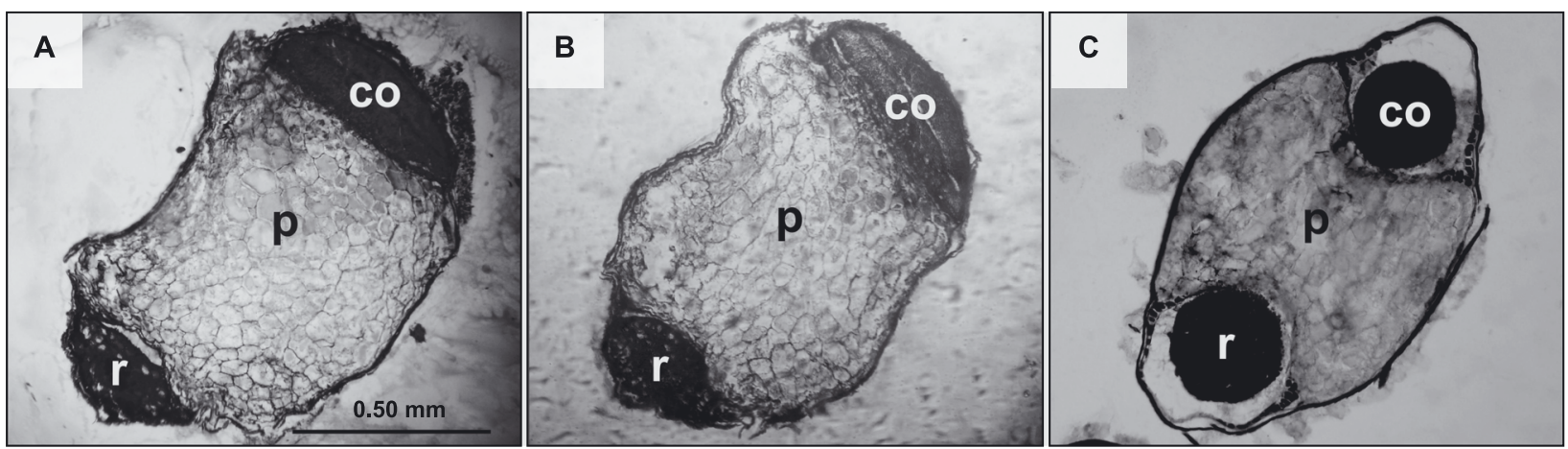

Fig. 2. Hystological sections of artificially discoloured seed (A) and naturally discoloured seed (B) both affected by Alternaria alternata, normal in appearance seed $(\mathrm{C})$ : radicle $(\mathrm{r})$, cotyledons $(\mathrm{co})$, perisperm $(\mathrm{p})$

Table 2. Fungal secondary metabolites: AOH - alternariol; AME - alternariol monomethyl ether; TEA - tenuazonic acid; ALT altenuene; ALTX-1 - altertoxine 1; TEN - tentoxin; LOD - limit of detection; detected on M1 - normal seeds; M2 - naturally discoloured seeds; M3 - artificially discoloured seeds and LPSC $\mathrm{N}^{\circ} 1085$ - strain of Alternaria alternata

\begin{tabular}{lcccccc}
\hline \multirow{2}{*}{ Samples } & \multicolumn{7}{c}{ Alternaria metabolites } \\
\cline { 2 - 7 } & AOH & AME & TeA & ALT & ALTX1 & TEN \\
\hline M1 $^{*}$ & 0.001 & 0.006 & 1.23 & $<$ LOD & $<$ LOD & 0.093 \\
M2 $^{*}$ & 0.923 & 16.88 & 4.66 & 0.03 & $<$ LOD & 0.430 \\
M3 $^{*}$ & 128,000 & 95,000 & $3,902,000$ & 33,000 & 9,400 & 94.03 \\
LPSC N $^{\circ} 1085^{* *}$ & 154.8 & 103.45 & 1155.5 & 69.45 & 2.34 & $<$ LOD \\
\hline
\end{tabular}

*values of mycotoxin concentration $\left[\mu \mathrm{g} \cdot \mathrm{g}^{-1}\right.$ of seeds]

** values of mycotoxin concentration $\left[\mu \mathrm{g} \cdot \mathrm{g}^{-1}\right.$ of media]

\section{Discussion}

The inoculation of normal seeds with A. alternata allowed us: i) to reproduce the discolouration of their coats and the hypertrophies of the perisperm and embryo, phenomenon observed on naturally infected seeds and ii) to identify four similar metabolites detected on natural and artificially discoloured seeds and an strain of A. alternata (LPSC $N^{\circ} 1085$ ) used in order to induce artificial seed discolouration.

The deep-freezing technique appeared more suitable as compared to previous method (Noelting et al. 2011) for induce the discolouration symptoms in amaranth seeds. This technique was positive since all seeds inoculated with A. alternata showed change of colour seed discolouration was more intense compared with the conidial suspension inoculation technique used in a previous report (Noelting et al. 2011).

On the other hand, the histopathological analysis and plating components allow us to observe the presence of propagules of A. alternata in all discoloured seed tissues. These results are consistent with those reported by Agrawal et al. (1987) and Ôzer (2005) for wheat grains affected by black-point. Moreover, plating components technique can locate the presence of propagules (mycelium and conidia) of A. alternata in different tissues of seeds.

The observed hypertrophies in the embryo and perisperm would be associated with a more severe infection by $A$. alternata and also various fungal secondary metabolites might be involved. According to Knoche and Duvick
(1987) most of the toxins produced by Alternaria have low molecular weight and can cause physiological and pathological changes in the host.

Therefore, it is possible that the morphological changes observed in the embryo and perisperm of discoloured seeds may have been the result of the action of fungal secondary metabolites.

Besides, the presence of $A$. alternata hyphae on the perisperm and embryo of discolourated seeds indicates the infectious nature of this microorganism. Moreover, a higher concentration of $A$. alternata conidia next to the hilar region of amaranth seeds inoculated with the fungus was observed. This fact may indicate that the hilar region is the most vulnerable site for penetration and subsequent colonization of seminal tissues by A. alternata. Thus, we can infer that the infection of $A$. alternata could take place either in the early stages of seed development or post seed formation. These results indicate that A. alternata is a contaminant and infectious fungus, hence the epidemiological importance of seeds as a source of inoculum of this species as a causal agent of spots and blights on leaves of amaranth plants needs to be recognized (Sánchez-Enciso et al. 1990; Noelting et al. 2004; Pusz 2009b).

In relation to mycological analysis of seeds, we observed that the type and concentrations of Alternaria fungal secondary metabolites detected on normal appearance seeds in the present work are within the same range to those mentioned by Biasi et al. 2013. However, the data of discoloured seeds could not be confirmed due to the absence of previous reports in this type of seeds. 
The higher concentration of TeA on artificially discoloured seeds could be associated with the used inoculation technique, which favored the rapid colonization of seeds by the pathogen. This mycotoxin is considered as a non-host-specific phytotoxin produced by several fungi including A. alternata among others (Montemurro and Visconti 1992). Currently there are no legal limits or criteria set for fungal secondary metabolites produced by $\mathrm{Al}$ ternaria as is was stated by European Food Safety Authority (EFSA) that the contamination of natural products by this organism are not important (EFSA 2011). However, in this study, the detection of high concentrations of fungal secondary metabolites in naturally and artificially discoloured seeds indicates a potential risk for consumers.

For this reason we believe it is advisable to consider strategies inherent to crop management and storage of production in order to reduce the level of fungal secondary metabolites in seeds.

\section{Conclusions}

The results found in this work indicate that A. alternata is a contaminant and infectious fungus species that is capable to alter seminal tissues and to produce secondary metabolites, which may affect quality and food security of amaranth seeds.

To our knowledge, the information presented in this paper, related to physiological, histopathological changes and fungal secondary metabolites on discoloured seeds of Amaranthus mantegazzianus syn. A. caudatus subsp. mantegazzianus (Pass.) Hanelt affected by A. alternata, is the first worldwide record.

\section{Aknowledgements}

We acknowledge the Universidad Nacional de La Plata for financial assistance in this study.

The LC-MS/MS system was funded by the Federal Country Lower Austria (grant number: Technopol 085) and co-financed by the European regional development fund of the European Union.

\section{References}

Afolabi A.O., Oke O.L., Umoh B. 1981. Preliminary studies on the nutritive value of some cereal-like grains. Nutrition Reports International 24: 389-394.

Agrawal K., Sharma J., Singh T., Singh D. 1987. Histopathology of Alternaria tenuis infected black pointed kernels of wheat. Botanical Bulletin Academia Sinica 28: 123-130.

Bartolini J.S., Hampton J.G. 1989. Grain amaranth - seed development, yield and quality. Proceedings Agronomy Society New Zealand 19: 55-61.

Becker R., Wheeler E.L., Lorenz K., Stafford A.E., Grosjean O.K., Betschart A.A., Saunders R.M. 1981. A compositional study of amaranth grain. Journal of Food Science 46 (4): 11751180.

Biasi A., Zachetti V., Oviedo M.S., Reynoso M.M., Ramirez M.L. 2013. Presencia de especies de Alternaria y sus micotoxinas en semillas de amaranto. [Presence of Alternaria species and mycotoxins un amaranth seeds]. p 101. In: Proccedings of VII Congreso Latinoamericano de Micotoxicología, Río Cuarto, Córdoba, Argentina, 2-6 December 2013, 190 pp. (in Spanish)

Bottalico A., Logrieco A. 1992. Alternaria plant diseases in Mediterranean countries and associated fungal secondary metabolites. p. 32. In: "Alternaria: Biology Plant Diseases and Metabolites" (J. Chelkowski, A. Visconti, eds.). Elsevier 209, Amsterdam, The Netherlands, 573 pp.

Conner R.L., Davidson J.G.N. 1988. Resistance in wheat to black point caused by Alternaria alternata and Cochliobolus sativus. Canadian Journal of Plant Science 68: 351-359.

D’Ambroggio de A.A. 1986. Manual de Técnicas en Histología Vegetal [Manual Techniques in Plant Histology]. Hemisferio Sur Editorial, Buenos Aires, Argentina, 83 pp. (in Spanish)

EFSA. 2011. Panel on Contaminants in the Food Chain Scientific opinion on the risks for animal and public health related to the presence of Alternaria toxins in feed and food. European Food Safety Authority (EFSA) Journal 9 (10): 2407.

Knoche H.W., Duvick J.P. 1987. The role of fungal toxins in plant disease. p. 158-192. In: "Fungal Infection of Plants" (G.F. Pegg, P.G. Ayres, eds.). Cambridge University Press, Cambridge, UK, $430 \mathrm{pp}$.

Limonard T. 1966. A modified blotter test for seed health. Netherland Journal of Plant Pathology 72: 319-321.

Lorenz K. 1986. Effects of black point on grain composition and baking quality of New Zealand. New Zealand Journal of Agricultural Research 29: 711-718.

Malachová A., Sulyok M., Beltrán E., Berthiller F., Krska R. 2014. Optimization and validation of a quantitative liquid chromatography-tandem mass spectrometric method covering 295 bacterial and fungal metabolites including all regulated mycotoxins in four model food matrices. Journal of Chromatography A 1362: 145-156.

Makus D.J., Davis D.R. 1984. A mid-summer crop for fresh greens or canning vegetable amaranth. Arkansas Farm Research 33 (3): 10.

Mathur S.B., Cunfer B. 1993. Black point. p. 13-21. In: "Seedborne Diseases and Seed Health Testing of Wheat" (S.B. Mathur, B. Cunfer, eds.). Danish Government Institute of Seed Pathology for Developing Countries, Copenhagen, Denmark, 168 pp.

Mathur S.B., Kongsdal O. 2003. Common Laboratory Seed Health Testing Methods for Detecting Fungi. International Seed Testing Association (ISTA), Bassersdorf, Switzerland, $425 \mathrm{pp}$.

Montemurro N., Visconti A. 1992. Alternaria metabolites-chemical and biological data. p. 449-541. In: “Alternaria: Biology Plant Diseases and Metabolites" (J. Chelkowski, A. Visconti, eds.). Elsevier 209, Amsterdam, The Netherlands, 32 pp. Moreno-Velázquez M., Yáñez-Morales M.J., Rojas-Martínez R.I., Zavaleta-Mejía E., Trinidad-Santos A., Arellano-Vázquez J.L. 2005. Diversidad de hongos en semilla de amaranto (Amaranthus hypochondriacus L.) y su caracterización molecular [Fungal diversity in amaranthus (Amaranthus hypochondriacus L.) seed and their molecular characterization]. Revista Mexicana de Fitopatología 23: 111-118. (in Spanish, with English summary)

NRC (National Research Council). 1984. Amaranth: Modern Prospects for an Ancient Crop. National Academy Press, Washington, DC, USA, $76 \mathrm{pp}$. 
Noelting M.C., Sandoval M.C., Abiatti N.N. 2004. Determinación de micoorganismos en semillas de amaranto en diferentes medios de cultivo [Determination of fungi microorganism on amaranth seeds (Amaranthus spp.) by different analysis methods]. Revista Peruana de Biología 11 (2): 169-178 (in Spanish)

Noelting M.C., Sisterna M.N., Lori G., Sandoval M.C., Molina M., Mónaco C.I. 2011. First report of Alternaria alternata causing discolouration on Amaranthus seeds in Argentina. Australasian Plant Disease Notes 6 (1): 1-2.

Özer N. 2005. Determination of the fungi responsible for black point in bread wheat and effects of the disease on emergence and seedling vigor. Trakya University Journal Science 6 (1): $35-40$.

Pusz W. 2009a. Fungi from seeds of Amaranthus spp. Phytopathología 54: 15-21.

Pusz W. 2009b. Valuation of the healthiness of Amaranthus leaves. Zeszyty Naukowe Uniwersytetu Przyrodniczego we Wrocławiu - Rolnictwo 95 (574): 51-61.

Samson R.A., Hoekstra E.S., Lund F., Filtenborg O., Frisvad J.C. 2002. Method for the detection, isolation and characteriza- tion of food-borne fungi. p. 283-297. In: "Introduction to Food and Airborne Fungi" (R.A. Samson, E.S. Hoekstra, J.C. Frisvad, O. Filtenborg, eds.). Centraalbureau voor Schimmecultures Utrecht, Utrecht, The Netherlands, 389 pp.

Sánchez Eneiso E.M., Osada K.S., Téliz O.D., Espitia R.E., Rendom S.G. 1990. Etiología e incidencia de la mancha negra del tallo em Amaranthus sp. y otras enfermedades [Etiology and incidence of the stem black spot and other diseases in Amaranthus sp.]. Revista Mexicana de Fitopatología 8: 102.106 (in Spanish)

Teutonico R.A., Knorr D. 1985. Amaranth: composition, properties and applications of a rediscovered food crop. Food Technology 39: 49-60.

Theerthagiri A., Ramanujam B., Thiruvengadam R., Gandhi K., Manikam R., Govindasamy S. 2008. Production of cell wall degrading enzymes and toxins by Colletotrichum capsici and Alternaria alternata causing fruit rot of chillies. Journal of Plant Protection Research 48 (4): 437-451.

Willis R.B.H., Wong A.W.K., Scriven F.M., Greenfield H. 1984. Nutrient composition of Chinese vegetables. Journal of Agricultural and Food Chemistry 32: 413-416. 